\title{
Justus-Liebig-Universität Gießen Library Holding ISBN: 9788366675599
}

\author{
Justus-Liebig-Universität Gießen
}

Ludwigstraße 23, 35390 Gießen, Germany

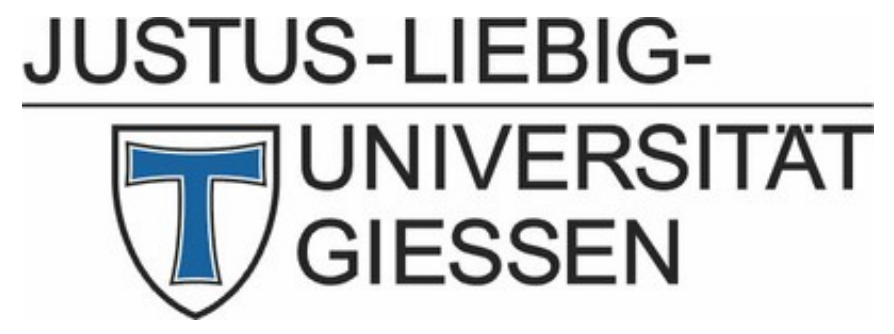

Library Holding:

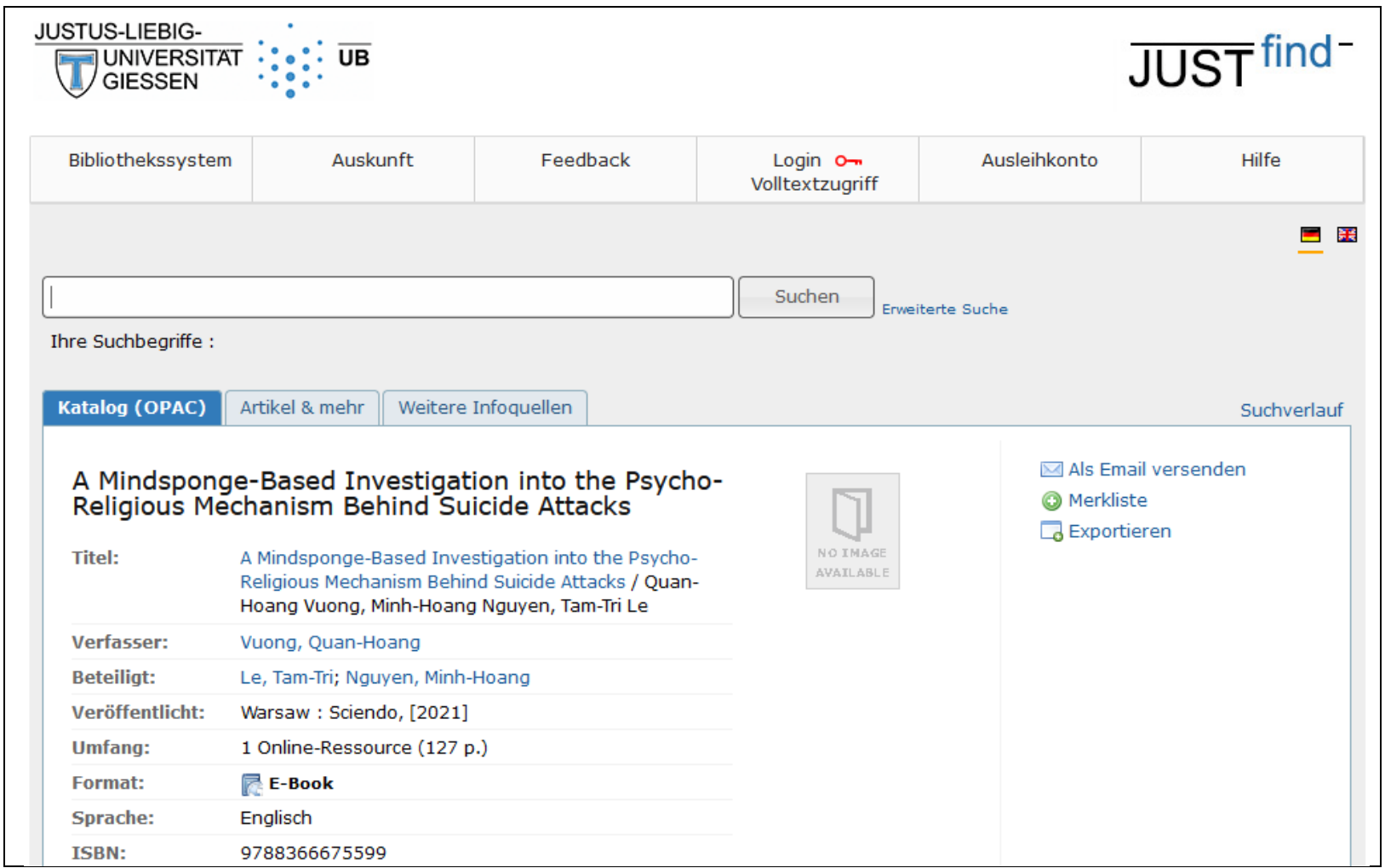




\section{Fantasio}

Testserver HeBIS Discovery System

\section{A Mindsponge-Based Investigation into the Psycho- Religious Mechanism Behind Suicide Attacks}

\section{Titel:}

A Mindsponge-Based Investigation into the PsychoReligious Mechanism Behind Suicide Attacks / QuanHoang Vuong, Minh-Hoang Nguyen, Tam-Tri Le

Verfasser: Vuong, Quan-Hoang

Beteiligt: Le, Tam-Tri; Nguyen, Minh-Hoang

Veröffentlicht: Warsaw : Sciendo, [2021]

Umfang: 1 Online-Ressource (127 p.)

Format:

$$
\text { E-Book }
$$

Sprache:

Englisch

ISBN:

9788366675599

Hinweise zum

Inhalt:

Bemerkung: Description based on online resource; title from PDF title page (publisher's Web site, viewed 29. Jul 2021)

Zusammenfassung: The book examines the psycho-religious mechanism behind the violent extremism of suicide attacks in the post-9/11 world. It employs the mindsponge concept, an original dataset, and original research results obtained from the authors' statistical investigations using the Hamiltonian Markov chain Monte Carlo technique. It provides insights and implications for policymakers and strategists in their efforts to engage in peace talks and reduce violent conflicts worldwide. 
*Permalink:

https://hds.hebis.de/ubgi/Record/HEB484063863

(Accessed: September 19, 2021) 